\title{
Global Calculations of Local and Remote Near-Inertial-Wave Dissipation
}

\author{
MAtThew H. AlFord \\ Scripps Institution of Oceanography, University of California, San Diego, La Jolla, California
}

(Manuscript received 15 May 2020, in final form 9 August 2020)

\begin{abstract}
Global estimates are presented of the fraction $q$ of wind-generated near-inertial wave power available for local turbulent dissipation under the assumption that modes 1-3 propagate "far" and the higher modes remain to eventually break. Using climatological stratification profiles and mixed layer depth, the modal distribution of near-inertial energy flux is computed following Gill's classic 1984 work by projecting a slab flow in the mixed layer onto the dynamical modes. Global maps and zonal-mean profiles are presented, which show a globalmean value of $q=0.63$ and 0.75 for winter and summer profiles, respectively. The simplicity of the calculation makes it of potential use in parameterizations of near-inertial breaking in climate simulations.
\end{abstract}

KEYWORD: Internal waves

\section{Introduction}

The sensitivity of climate simulations to the representation of internal wave breaking has been demonstrated Jochum et al. (2013), Melet et al. (2013), and MacKinnon et al. (2017). Though the power input to internal tides and near-inertial mixed layer motions is the same order of magnitude [Egbert and Ray (2000) and Alford (2003a); but see Alford (2020)], internal tides have received far more attention primarily owing to their greater degree of observations via altimetry (Zhao et al. 2016) and their smaller intermittency compared to near-inertial waves (NIW).

Parameterization of internal-tide mixing has proceeded following St. Laurent et al. (2002):

$$
\varepsilon(x, y, z)=q F(z) C(x, y),
$$

where $F(z)$ is a unity-normalized structure function, $C$ is the conversion rate of barotropic to baroclinic energy, and $q$ [assumed by St. Laurent et al. (2002) to be 0.3] is the locally dissipated fraction. The other portion of the energy, which radiates away in low modes, is dissipated elsewhere, as modeled by Eden and Olbers (2014) and de Lavergne et al. (2019). More recent work (Vic et al. 2019) has shown that $q \approx$ 0.6 , and moreover is quite spatially variable, as would be expected given the variability in the bottom bathymetry (e.g., sharp, supercritical ridges give a "redder" modal distribution and lower $q$ while spreading centers with subcritical topography such as the mid-Atlantic Ridge give more high-mode energy and local dissipation). Variability in $q$ likely leads to climate sensitivity for a variety of reasons; for example, the depth distribution of turbulence due to long-propagating waves that break remotely differs from that associated with local generation (Cimoli et al. 2019). It is this depth dependence that gives rise to the strongest climate sensitivity (Melet et al. 2013).

Here, a very simple theoretical estimate is given of $q$ for NIW, following the formalism of Gill (1984). Using climatological

Corresponding author: Matthew H. Alford, malford@ucsd.edu stratification and wintertime mixed layer depth, the approach projects slab mixed layer flow onto the dynamical modes, obtaining the modal distribution of flux into each mode. Following Vic et al. (2019), modes 1-3 are assumed to propagate far enough away so as to be designated nonlocal; $q$ is then defined as the fraction of the flux in modes 4 and higher.

\section{Approach and methods}

The approach taken in the classic work of Pollard (1970) and Gill (1984) is to assume that the momentum input by the wind is deposited into a slab-like mixed layer of depth $H$. That step velocity profile is then projected onto the flat-bottom horizontal dynamical modes, a set of basis functions obtained by solving the Sturm-Liouville problem,

$$
\frac{\partial^{2}}{\partial z^{2}} \eta(z)+\frac{N^{2}(z)}{c_{n}^{2}} \eta(z)=0,
$$

subject to the boundary conditions $\eta(0)=\eta(D)=0$, where $D$ is the water depth, $n$ the mode number, and $c_{n}$ the eigenspeed. Equation (2) gives the vertical modes for vertical displacement $\eta$; the horizontal modes $\Phi(z)$ for velocity are calculated by continuity as the vertical derivative (Gill 1982).

The initial normalized velocity step function $S(z)$ (1 down to a depth $z=H$; 0 beneath) is then represented as a weighted sum of these modes, where the modal amplitude distribution will be of central interest here:

$$
S(z)=\sum_{n}^{\infty} a_{n} \Phi(z)
$$

Propagation of near-inertial energy in the interior occurs as the different modes, with their different frequencies as given by the dispersion relation, rotate and become dephased relative to one another (Gill 1984; D'Asaro et al. 1995). Importantly, the wind work on each mode can be similarly decomposed (Furuichi et al. 2008): 

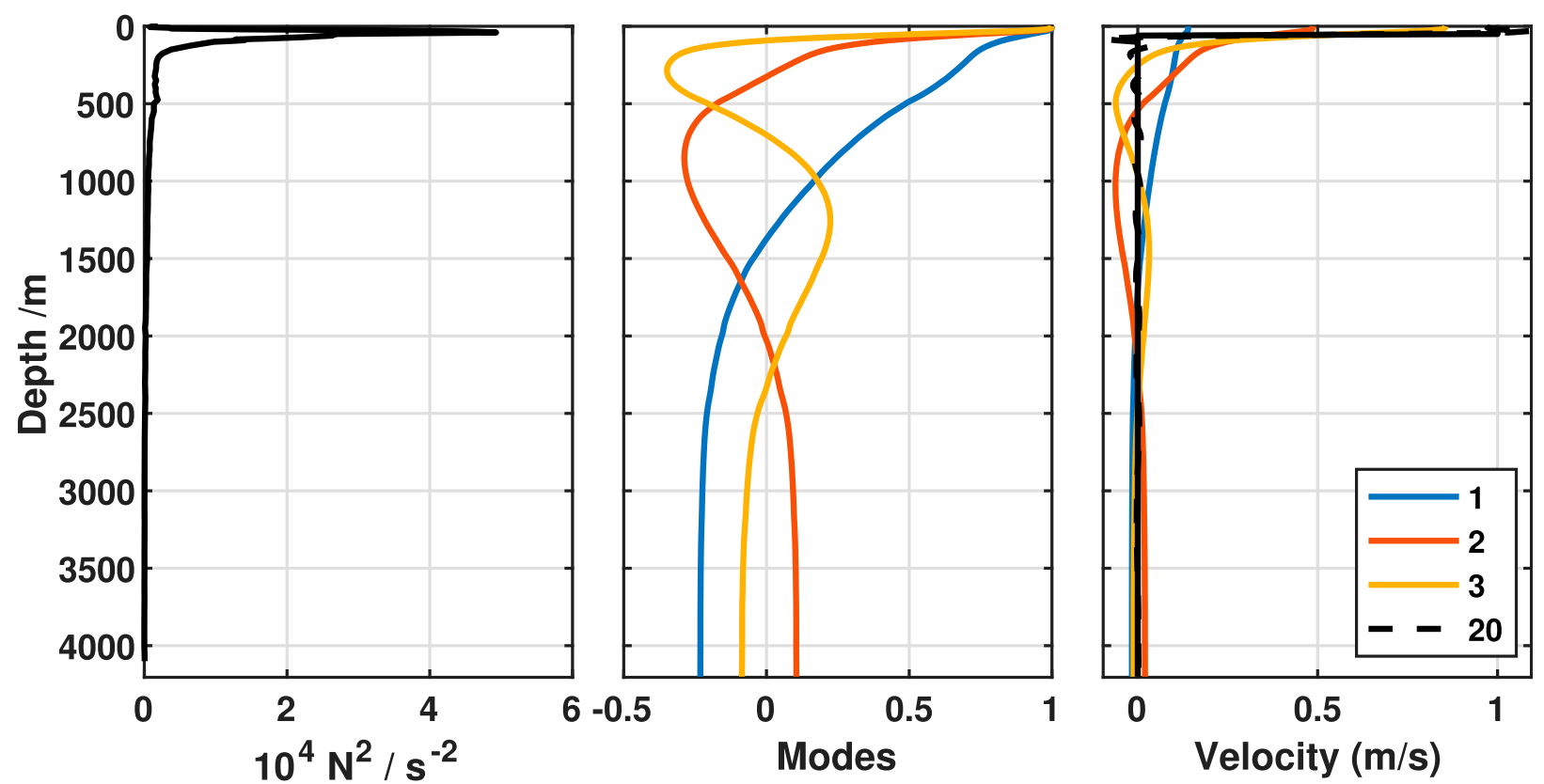

FIG. 1. Sample calculation for a location in the tropical Pacific $\left(10^{\circ} \mathrm{S}, 90^{\circ} \mathrm{W}\right)$ : (left) $N^{2}$, (center) the first three dynamical modes computed by solving (2), and (right) the initial slab profile (black) and the solution summing up to the indicated number of modes (dashed).

$$
\boldsymbol{\tau} \cdot \mathbf{u}=\boldsymbol{\tau} \cdot \sum_{n}^{\infty} \mathbf{a}_{n} \Phi(z)
$$

We ignore the significant reduction of the energy available to propagating NIW relative to the wind work due to turbulence (Alford 2020), and will return to this issue below. We will furthermore focus only on the magnitude distribution rather than the vector quantities:

$$
|\boldsymbol{\tau} \cdot \mathbf{u}|=|\boldsymbol{\tau}| \sum_{n}^{\infty}\left|a_{n}\right| \Phi(z)
$$

Hence, the relative flux into each propagating mode is proportional to $\left|a_{n}\right|$. Note that because the step function has unity amplitude, the modal amplitudes can be interpreted either as velocities in meters per second for a $1 \mathrm{~m} \mathrm{~s}^{-1}$ mixed layer current, or as the fractional amplitude of the total solution
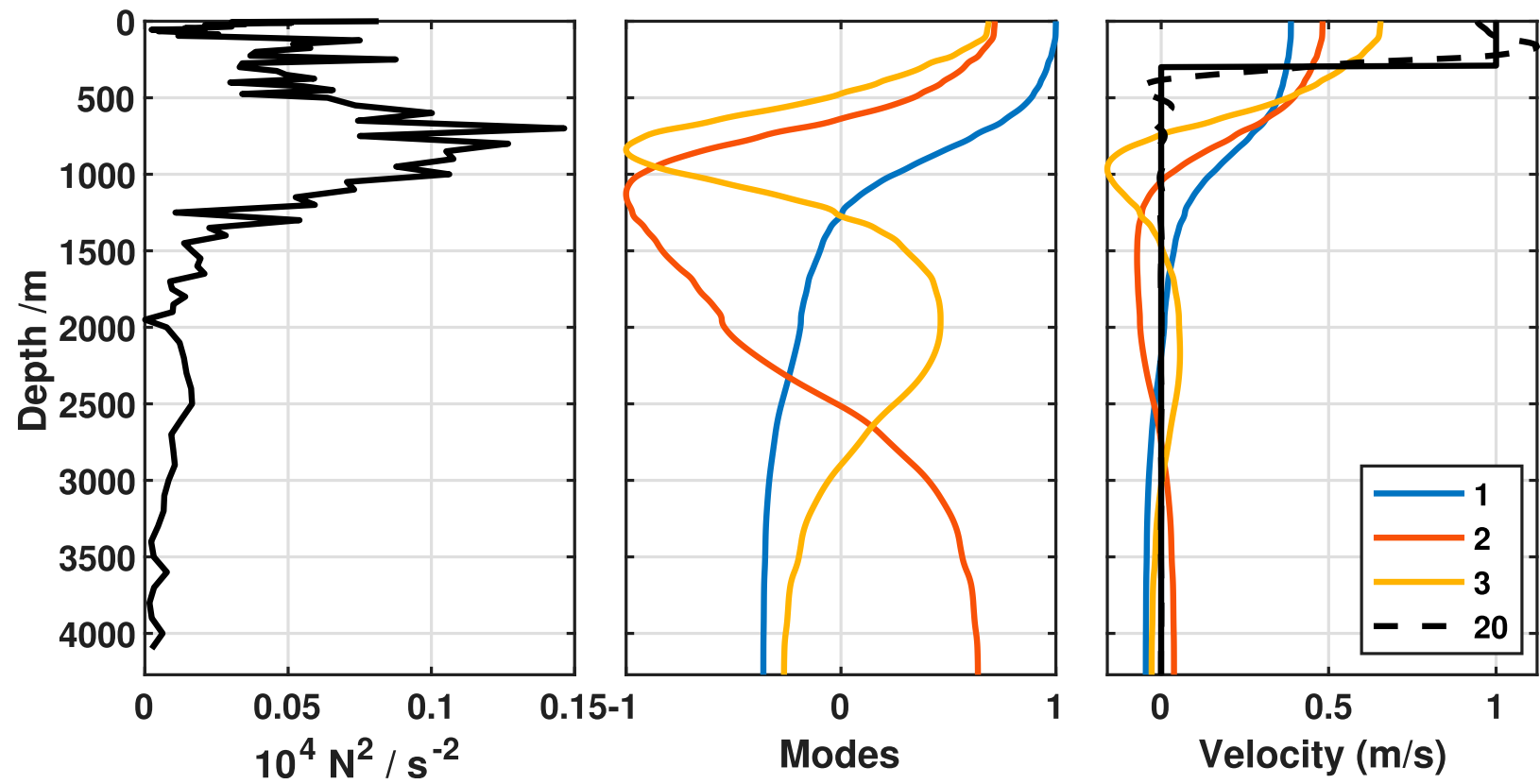

FIG. 2. As in Fig. 1, but for a location in the Atlantic $\left(45^{\circ} \mathrm{N}, 20^{\circ} \mathrm{W}\right)$. Note different scale for $N^{2}(z)$. 


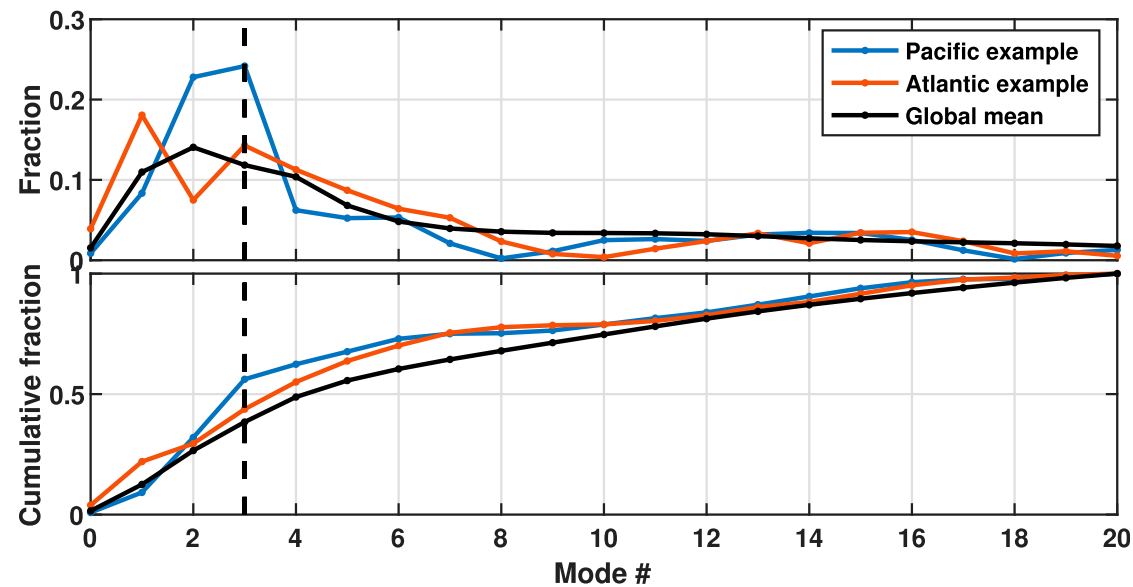

FIG. 3. (top) Amplitude vs mode number for the stratifications in Figs. 1 and 2 (blue, red) and the global mean (black). (bottom) The cumulative sum. Mode 3 is indicated.

for each mode. From (4), this is also the fraction of the flux in that mode, which differs from the $a_{n}^{2}$ modal distribution for energy.

It is noted that Gill's approach was intended for fast-moving storms; however, slow-moving storms affect the phasing of the response but not the modal distribution. Additionally noting that most near-inertial forcing is due to fast-moving midlatitude storms (e.g., D’Asaro 1985; Alford 2001), we proceed cautiously.

The calculation is demonstrated using $N^{2}(z)$ profiles computed from temperature and salinity taken from the World Ocean Atlas 2018 (Locarnini et al. 2018; Zweng et al. 2018) for the tropical Pacific at $10^{\circ} \mathrm{S}, 90^{\circ} \mathrm{W}$ (Fig. 1) and the North Atlantic at $45^{\circ} \mathrm{N}, 20^{\circ} \mathrm{W}$ (Fig. 2). Bottom depth $D$ is taken from version 20 of Smith and Sandwell (1997). Stratification profiles (left) are representative of each basin; notable differences include the shallower seafloor depth and the deeper, more diffuse thermocline in the Atlantic.

The first three dynamical modes $\Phi(z)$ are shown in the center panel of Figs. 1 and 2. All show the usual enhancement in amplitude and wavenumber in the upper ocean expected from Wentzel-Kramers-Brillouin (WKB) theory (Gill 1982) for surface-intensified stratification. The mode- 2 zero crossing is shallower in the Pacific ( $600 \mathrm{~m}$ versus $800 \mathrm{~m}$ ) owing to the shallower thermocline.

The slab velocity profile is shown at right (black) for typical wintertime mixed layer depths of $H=60$ and $350 \mathrm{~m}$ at each respective location. The sum of the amplitudes times the modal shapes $\Phi_{n}(z)$ for the indicated number of modes is overplotted. For 20 modes, the solution closely approximates the step function.

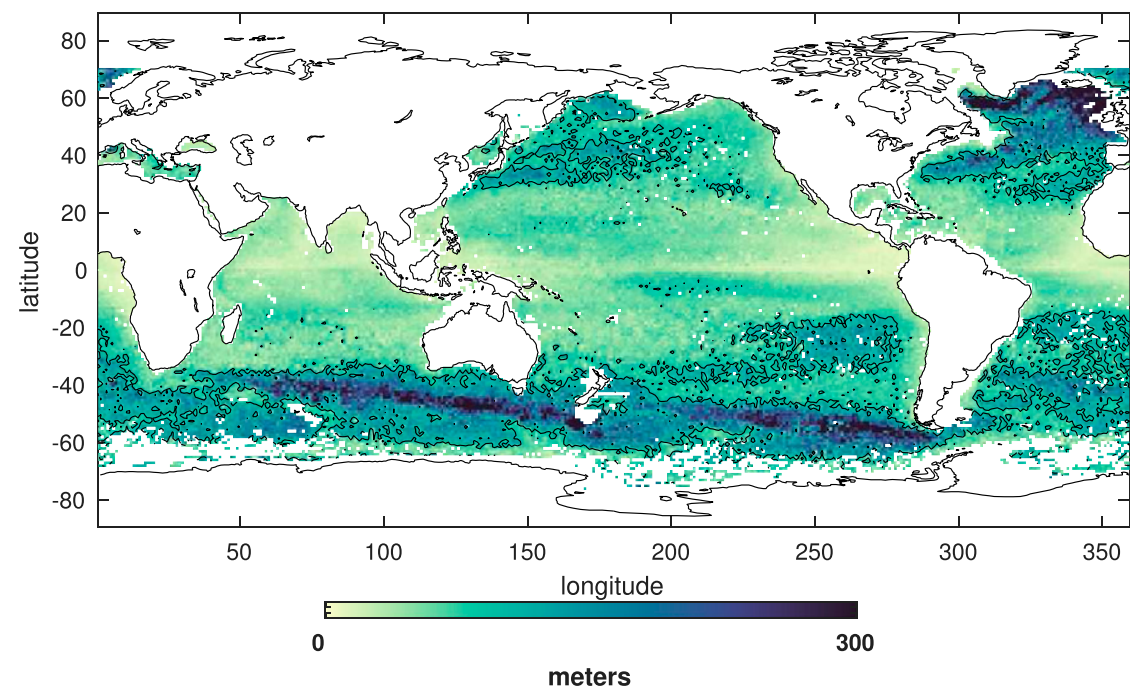

FIG. 4. Global map of wintertime mixed layer depth from Argo (Holte et al. 2017). Wintertime is defined as months 1-3 and 7-9 for the northern and Southern Hemisphere calculations, respectively; $H=100 \mathrm{~m}$ is contoured. 

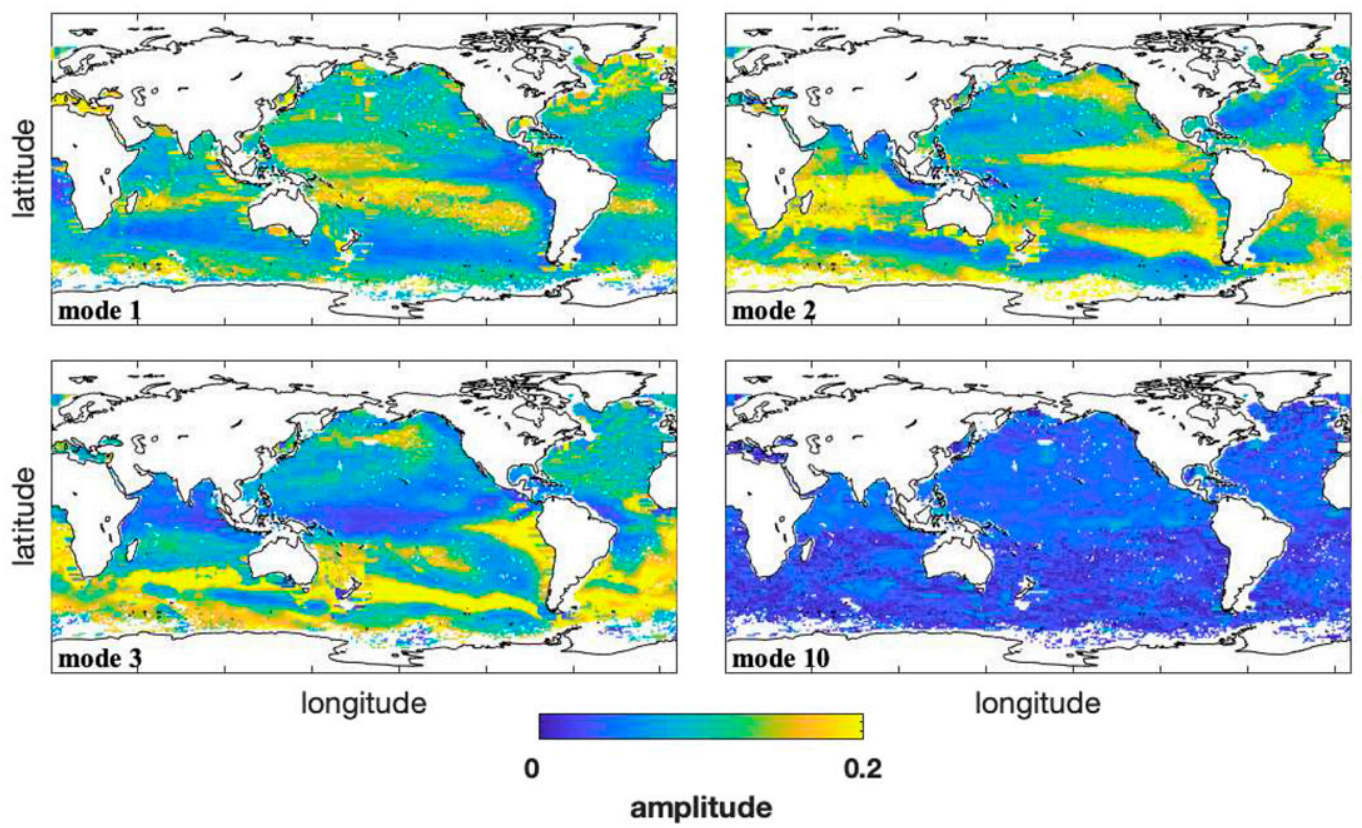

FIG. 5. Global map of amplitude in modes 1, 2, 3, and 10.

The modal amplitudes for each location comprise a red spectrum (Fig. 3, red, blue), with $36 \%-60 \%$ of the cumulative sum (bottom) contained in the first three modes $(1-q)$. Intuitively, deeper mixed layers are expected to project more strongly onto mode 1 , which is seen. However, the combination of the shallower Pacific thermocline and shallower mixed layer depth increases the projection onto modes 2 and 3, so that the total of the first three modes is actually higher in the Pacific. The locally dissipated fraction $q \equiv \sum_{4}^{20} a_{n}$ is 0.45 and 0.60 for the Pacific and Atlantic examples, respectively.

\section{Global calculations}

Following the sample calculations above, it is straightforward to extend the calculation to the global oceans. Stratification $N^{2}(z)$ is taken from the World Ocean Atlas 2018 (Locarnini et al. 2018; Zweng et al. 2018) and water depth $D$ is from version 20 of Smith and Sandwell (1997). Mixed layer depth $H$ is taken from the monthly Argo-based climatology of Holte et al. (2017). To approximate wintertime generation of NIW, $H$ is taken when the annual cycle of wind work is the greatest in each hemisphere (Alford 2003a); namely, months 1-3 and 7-9 in the Northern and Southern Hemispheres, respectively (Fig. 4). For comparison, summertime mixed layer depths are computed for months 7-9 and 1-3 for each hemisphere, respectively.

The global distribution of the fractional flux into modes 1, 2, 3, and 10 is presented in Fig. 5. While the maps are straightforward to compute, the results are not always intuitive. Nonetheless, some expected patterns emerge such as large mode-1 amplitudes in the North Atlantic where $H$ is large. In the equatorial Pacific, the step profile projects more strongly onto mode 2 to the east, as the thermocline shoals in response to the trade winds. The spectrum is red for mode numbers 2 and higher at all locations, as seen by the much-reduced mode-10 amplitudes (Fig. 5d) relative to the lower modes and the global mean spectrum (Fig. 3, black).

The local fraction $q$, the primary result of this short note, is then the sum of modes 4-20 (Fig. 6), which is plotted for winter (when most generation occurs; Fig. 6a) and for summer (Fig. 6b) for comparison. The zonal mean varies from 0.4 to 0.7 , following more or less the inverse of $H$ (Fig. 7), with a global mean of 0.63 . In summer, $q$ is greater as expected given the shallower mixed layer depths, with a global mean of 0.75 .

Random errors in our $q$ estimate are indicated as \pm 1 standard deviation in Fig. 7. A brief sensitivity analysis of systematic errors associated with our methods and assumptions is shown in Fig. 8, indicating that they do not materially affect our results. First, $q$ is estimated using $H 20 \%$ deeper than the Holte et al. (2017) values, following findings by Crawford and Large (1996) and others that momentum can penetrate somewhat deeper than the mixed layer. The associated $q$ (red) with deeper momentum penetration is approximately $7 \%-8 \%$ smaller as expected owing to the greater projection onto lower modes. Using only the first month of the winter rather than the whole period (green) introduces a small amount of extra scatter, but the mean values are nearly unchanged relative to the winter-mean calculations. Using temperature rather than density to determine $H$ (magenta) gives values $6 \%$ lower, with a global mean of 0.61 rather than 0.63 . Finally, the dependence on our choice of cutoff mode number can be simply read off of the global mean curve (black) in Fig. 3b. Choosing cutoff mode numbers 2 and 4 instead of 3 gives global-mean $q$ of 0.75 and 0.52 , respectively. 

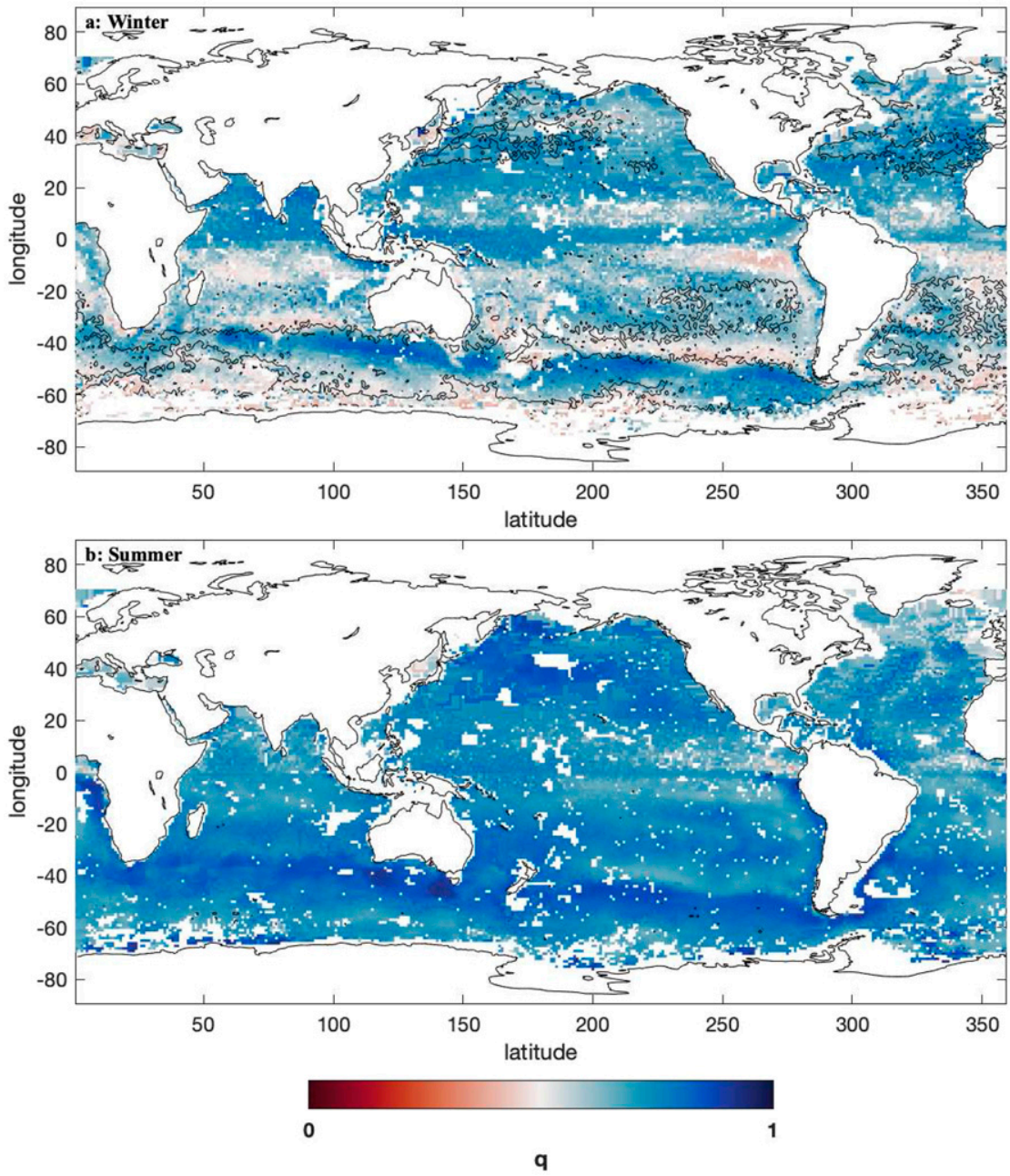

FIG. 6. Global map of $q$ for (a) winter and (b) summer. Mixed layer depth $H=100 \mathrm{~m}$ is contoured in (a).

\section{Discussion}

In this simple calculation we have assumed that the slab model is a valid representation of momentum deposition in the mixed layer by resonant forcing, which has considerable observational support (Pollard and Millard 1970; D'Asaro et al. 1995; Alford 2001), but ignores many subtleties (Crawford and Large 1996; Plueddemann and Farrar 2006; Alford 2020). We have also ignored a host of processes known to impact NIW propagation including modulation by the mesoscale and preferential propagation in anticyclonic "chimneys" (Lee and Niiler 1998; Zhai et al. 2005). Still, while mesoscale effects are known to impact the lateral scales, time scale, and depth penetration of NIW, they are unlikely to significantly alter the modal distribution of the generated waves.

The result that $q \approx 0.5-0.7$ is in line with experimental results from the Ocean Storms Experiment (D'Asaro et al. 1995), which reported $37 \%$ of energy departing the region laterally in modes 1 and 2, as well as global measurements of lateral NIW energy fluxes from Alford (2003b) suggesting that $12 \%-50 \%$ of energy radiates away in modes $1-2$. These findings were generally supported by modeling studies (Zhai et al. 2007; Furuichi et al. 2008; Simmons and Alford 2012).

The quantification here of $q$ is therefore but a modest step forward; its utility is perhaps in its potential for simple and computationally inexpensive implementation in climate models. Importantly, it can be run with the evolving stratification and mixed layer depth fields, allowing the NIWdriven mixing to evolve in future climate states. Given the special importance of NIW to the tropics (Jochum et al. 2013), the elevated $q \approx 0.72$ near the equator may be significant here, though equatorial near-inertial waves require special consideration beyond the scope of this article since $f$ changes over comparable distances to NIW wavelengths. On the other hand, $q$ varies little enough globally that use of $q \approx$ 0.63 is probably justifiable, and preferable to $q=0.3$.

Parameterized near-inertial wave breaking has been demonstrated to yield sensitivity in the Community Climate System Model version 4 (CCSM4) model (Jochum et al. 

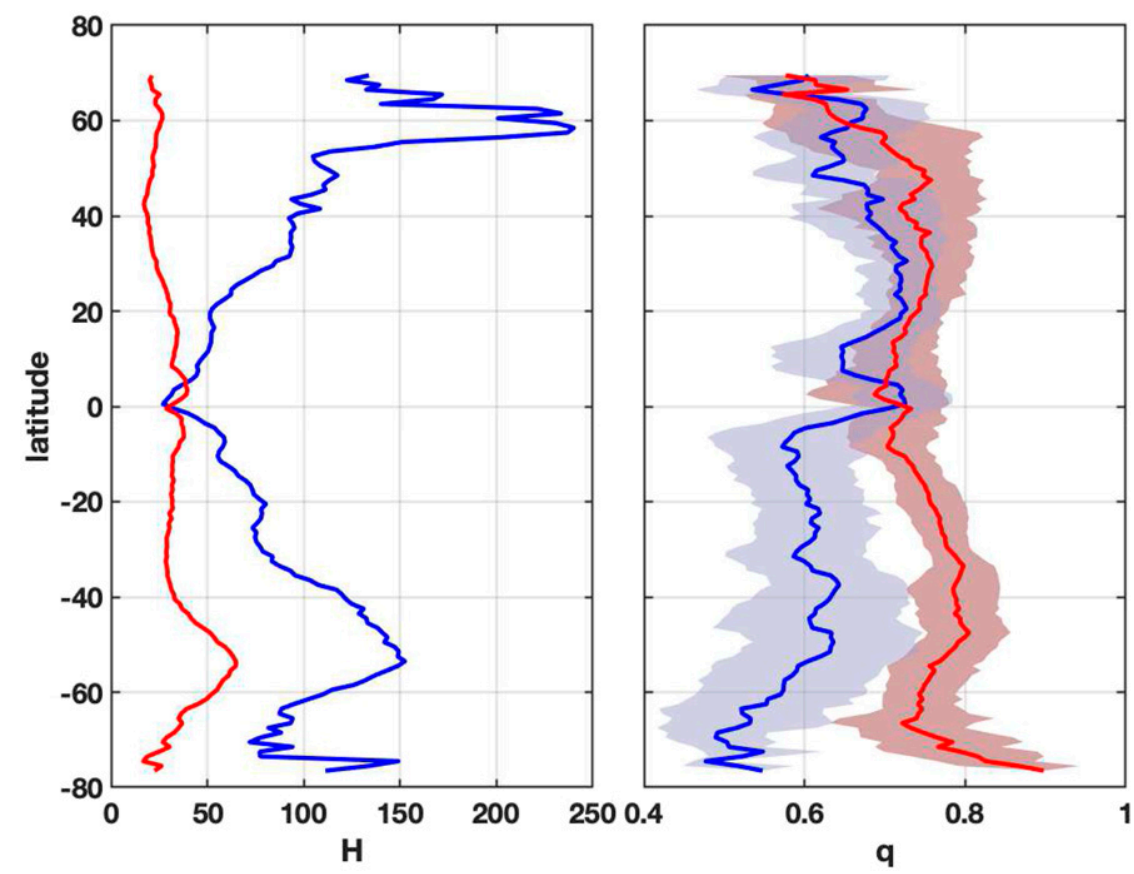

FIG. 7. Zonal-mean plots of $H$ and $q$ for winter (blue) and summer (red). Shading at right is \pm 1 standard deviation.

2013) using a similar formalism as (1), assuming a constant $q=0.5$ and that $70 \%$ of the energy was dissipated in deepening the mixed layer; the remainder was assumed to scale as $N^{2}(z)$. With these assumptions, Jochum et al. (2013) found that the primary impact of NIW mixing was in increased mixed layer deepening; diffusivity was only weakly elevated over background diffusivities. This finding is roughly consistent with the findings of Whalen et al. (2018) that wintertime/summertime diffusivity is $\approx 10^{-5}$ and $\approx 10^{-6} \mathrm{~m}^{2} \mathrm{~s}^{-1}$, respectively. If the modulation is interpreted as due to NIW, then their diffusivity is similar to that typically used for background mixing in models. Given the uncertainties remaining in all of these assumptions, considerable room for alternate interpretations remains.

Finally, the fate of the low modes that radiate away remains unknown (Fu 1981; Garrett 2001), though they have been observed to preferentially radiate toward the equator, as expected given their generation near their turning latitude (Alford 2003b). Because of their long vertical scales, they are unlikely to interact rapidly with the rest of the internal wave spectrum, leaving them free to propagate long distances with little dissipation in like manner to lowmode internal tides. However, in contrast to internal tides whose long-distance propagation can be tracked via altimetry (Ray and Mitchum 1996; Ray and Cartwright 2001; Zhao et al. 2016; Alford et al. 2019), long-distance radiation of low-mode NIW is very poorly constrained and only measured in a few studies (Alford 2003b; Alford and Zhao 2007a,b). Near-inertial propagation has been examined in a few numerical simulations (Nagasawa et al. 2000; Zhai et al. 2007; Furuichi et al. 2008; Simmons and Alford 2012), the first of which finding that they can undergo Parametric Subharmonic instability (PSI) when they reach a latitude where their frequency is twice the local $f$ (Nagasawa et al. 2000). It may be that the near-inertial low modes break preferentially near the continental margins as do the internal tides, but firm conclusions are not possible without more observations.

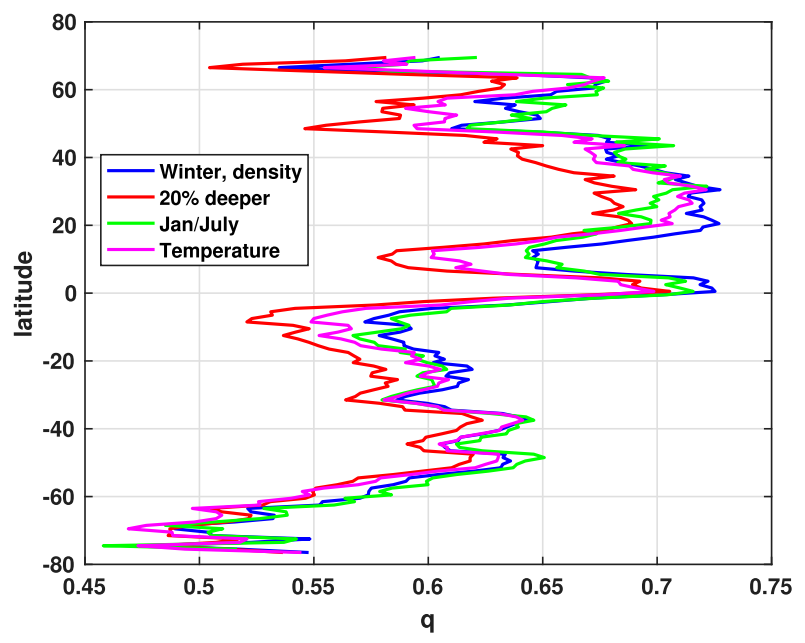

FIG. 8. Zonal-mean plots of wintertime $q$ computed using all three winter months as in Fig. 7 (blue), with $H 20 \%$ deeper (red), using only the first wintertime month (January/July depending on hemisphere, green) and using a temperature criterion for $H$ rather than density (magenta). 
Acknowledgments. This paper was written during the early stages of the COVID-19 outbreak and is dedicated to the heroic hospital workers and the many families that have lost loved ones. The author thanks Bill Young and Leif Thomas for useful comments early on. This work was supported by ONR Award N000141812404.

\section{REFERENCES}

Alford, M. H., 2001: Internal swell generation: The spatial distribution of energy flux from the wind to mixed layer near-inertial motions. J. Phys. Oceanogr., 31, 2359-2368, https://doi.org/ 10.1175/1520-0485(2001)031<2359:ISGTSD > 2.0.CO;2.

_, $2003 \mathrm{a}$ : Improved global maps and 54-year history of windwork on ocean inertial motions. Geophys. Res. Lett., 30, 1424 1427, https://doi.org/10.1029/2002GL016614.

- 2003b: Internal swell: Distribution and redistribution of internal-wave energy. Proc. Dynamics of Oceanic Internal Gravity Waves, II, 'Aha Huliko'a Hawaiian Winter Workshop, Honolulu, HI, Hawaii Institute of Geophysics, 29-40.

_ 2020: Revisiting near-inertial wind work: Slab models, relative stress and mixed layer deepening. J. Phys. Oceanogr., 50, 3141-3156, https://doi.org/10.1175/JPO-D-20-0105.1.

—_, and Z. Zhao, 2007a: Global patterns of low-mode internal-wave propagation, Part I: Energy and energy flux. J. Phys. Oceanogr., 37, 1829-1848, https://doi.org/10.1175/ JPO3085.1.

— propagation, Part II: Group velocity. J. Phys. Oceanogr., 37, 1849-1858, https://doi.org/10.1175/JPO3086.1.

—, H. L. Simmons, O. B. Marques, and J. B. Girton, 2019: Internal tide attenuation in the North Pacific. Geophys. Res. Lett., 46, 8205-8213, https://doi.org/10.1029/2019GL082648.

Cimoli, L., C. P. Caulfield, H. L. Johnson, D. P. Marshall, A. Mashayek, A. C. Naveira Garabato, and C. Vic, 2019: Sensitivity of deep ocean mixing to local internal tide breaking and mixing efficiency. Geophys. Res. Lett., 46, 14 622-14 633, https://doi.org/10.1029/2019GL085056.

Crawford, G., and W. Large, 1996: A numerical investigation of resonant inertial response of the ocean to wind forcing. J. Phys. Oceanogr., 26, 873-891, https://doi.org/10.1175/15200485(1996)026<0873:ANIORI >2.0.CO;2.

D'Asaro, E. A., 1985: The energy flux from the wind to nearinertial motions in the mixed layer. J. Phys. Oceanogr., 15, 1043-1059, https://doi.org/10.1175/1520-0485(1985)015<1043: TEFFTW $>2.0 . \mathrm{CO} ; 2$.

— C. E. Eriksen, M. D. Levine, P. Niiler, C. A. Paulson, and P. V. Meurs, 1995: Upper-ocean inertial currents forced by a strong storm. Part I: Data and comparisons with linear theory. J. Phys. Oceanogr., 25, 2909-2936, https://doi.org/10.1175/ 1520-0485(1995)025<2909:UOICFB > 2.0.CO;2.

de Lavergne, C., S. Falahat, G. Madec, F. Roquet, J. Nycander, and C. Vic, 2019: Toward global maps of internal tide energy sinks. Ocean Modell., 137, 52-75, https://doi.org/10.1016/ j.ocemod.2019.03.010.

Eden, C., and D. Olbers, 2014: An energy compartment model for propagation, nonlinear interaction, and dissipation of internal gravity waves. J. Phys. Oceanogr., 44, 2093-2106, https:// doi.org/10.1175/JPO-D-13-0224.1.

Egbert, G. D., and R. D. Ray, 2000: Significant dissipation of tidal energy in the deep ocean inferred from satellite altimeter data. Nature, 405, 775-778, https://doi.org/10.1038/ 35015531 .
Fu, L.-L., 1981: Observations and models of inertial waves in the deep ocean. Rev. Geophys. Space Phys., 19, 141-170, https:// doi.org/10.1029/RG019i001p00141.

Furuichi, N., T. Hibiya, and Y. Niwa, 2008: Model-predicted distribution of wind-induced internal wave energy in the world's oceans. J. Geophys. Res., 113, C09034, https://doi.org/10.1029/ 2008JC004768.

Garrett, C., 2001: What is the "near-inertial" band and why is it different from the rest of the internal wave spectrum? J. Phys. Oceanogr., 31, 962-971, https://doi.org/10.1175/1520-0485(2001) 031<0962:WITNIB > 2.0.CO;2.

Gill, A. E., 1982: Atmosphere-Ocean Dynamics. Academic Press, $662 \mathrm{pp}$.

— 1984: On the behavior of internal waves in the wake of a storm. J. Phys. Oceanogr., 14, 1129-1151, https://doi.org/ 10.1175/1520-0485(1984)014<1129:OTBOIW>2.0.CO;2.

Holte, J., L. D. Talley, J. Gilson, and D. Roemmich, 2017: An Argo mixed layer climatology and database. Geophys. Res. Lett., 44, 5618-5626, https://doi.org/10.1002/2017GL073426.

Jochum, M., B. P. Briegleb, G. Danabasoglu, W. G. Large, S. R. Jayne, M. H. Alford, and F. O. Bryan, 2013: The impact of oceanic near-inertial waves on climate. J. Climate, 26, 28332844, https://doi.org/10.1175/JCLI-D-12-00181.1.

Lee, D., and P. Niiler, 1998: The inertial chimney: The near-inertial energy drainage from the ocean surface to the deep layer. J. Geophys. Res., 103, 7579-7591, https://doi.org/10.1029/97JC03200.

Locarnini, R. A., and Coauthors, 2018: Temperature. Vol. 1, World Ocean Atlas 2018, NOAA Atlas NESDIS 81, 52 pp.

MacKinnon, J. A., and Coauthors, 2017: Climate process team on internal wave-driven ocean mixing. Bull. Amer. Meteor. Soc., 98, 2429-2454, https://doi.org/10.1175/BAMS-D-16-0030.1.

Melet, A., R. Hallberg, S. Legg, and K. L. Polzin, 2013: Sensitivity of the ocean state to the vertical distribution of internal-tidedriven mixing. J. Phys. Oceanogr., 43, 602-615, https://doi.org/ 10.1175/JPO-D-12-055.1.

Nagasawa, M., Y. Niwa, and T. Hibiya, 2000: Spatial and temporal distribution of the wind-induced internal wave energy available for deep water mixing in the North Pacific. J. Geophys. Res., 105, 13 933-13 943, https://doi.org/10.1029/2000JC900019.

Plueddemann, A., and J. Farrar, 2006: Observations and models of the energy flux from the wind to mixed-layer inertial currents. Deep-Sea Res. II, 53, 5-30, https://doi.org/10.1016/ j.dsr2.2005.10.017.

Pollard, R. T., 1970: On the generation by winds of inertial waves in the ocean. Deep-Sea Res. Oceanogr. Abstr., 17, 795-812, https://doi.org/10.1016/0011-7471(70)90042-2.

_ , and R. C. Millard, 1970: Comparison between observed and simulated wind-generated inertial oscillations. Deep-Sea Res. Oceanogr. Abstr., 17, 153-175, https://doi.org/10.1016/00117471(70)90043-4.

Ray, R. D., and G. T. Mitchum, 1996: Surface manifestation of internal tides generated near Hawaii. Geophys. Res. Lett., 23, 2101-2104, https://doi.org/10.1029/96GL02050.

, and D. E. Cartwright, 2001: Estimates of internal tide energy fluxes from TOPEX/Poseidon altimetry: Central North Pacific. Geophys. Res. Lett., 28, 1259-1262, https://doi.org/10.1029/ 2000 GL012447.

Simmons, H. L., and M. H. Alford, 2012: Simulating the long range swell of internal waves generated by ocean storms. Oceanography, 25, 30-41, https://doi.org/10.5670/oceanog.2012.39.

Smith, W. H. F., and D. T. Sandwell, 1997: Global sea floor topography from satellite altimetry and ship depth soundings. Science, 277, 1956-1962, https://doi.org/10.1126/science.277.5334.1956. 
St. Laurent, L. C., H. L. Simmons, and S. R. Jayne, 2002: Estimating tidally driven mixing in the deep ocean. Geophys. Res. Lett., 29, 2106, https://doi.org/10.1029/2002GL015633.

Vic, C., and Coauthors, 2019: Deep-ocean mixing driven by smallscale internal tides. Nat. Commun., 10, 2099, https://doi.org/ 10.1038/s41467-019-10149-5.

Whalen, C. B., J. A. MacKinnon, and L. D. Talley, 2018: Largescale impacts of the mesoscale environment on mixing from wind-driven internal waves. Nat. Geosci., 11, 842-847, https:// doi.org/10.1038/s41561-018-0213-6.

Zhai, X., R. J. Greatbatch, and J. Zhao, 2005: Enhanced vertical propagation of storm-induced near-inertial energy in an eddying ocean channel. Geophys. Res. Lett., 32, L18602, https://doi.org/10.1029/2005GL023643.

- - _ — , and C. Eden, 2007: Spreading of near-inertial energy in a $1 / 12^{\circ}$ model of the north Atlantic Ocean. Geophys. Res. Lett., 34, L10609, https://doi.org/10.1029/ 2007 GL029895.

Zhao, Z., M. H. Alford, J. B. Girton, L. Rainville, and H. L. Simmons, 2016: Global observations of open-ocean mode$1 \mathrm{M} 2$ internal tides. J. Phys. Oceanogr., 46, 1657-1684, https:// doi.org/10.1175/JPO-D-15-0105.1.

Zweng, M. M., and Coauthors, 2018: Salinity. Vol. 2, World Ocean Atlas 2018, NOAA Atlas NESDIS 82, 50 pp. 